\title{
Attachment Patterns and Their Relationship to Self-Assertion Among Secondary School Students
}

\author{
Anas Ramadan Ibrahim Al-Masri \\ Assistant Professor, Department of Counseling and Family rehabilitation \\ Faculty of Educational Sciences, Jadara University
}

\begin{abstract}
The study aimed to identify the nature of attachment patterns and their relationship to self-assertion among secondary school students at Tla al-Ali Secondary School for Girls. The sample which was selected in a random cluster method consisted of (250) female student at Tla al-Ali Secondary School in Amman. The researcher used the Pearson correlation coefficient and the regression equation to verify the study hypotheses. The study showed the following results: a) there is a correlation relationship with a negative statistical significance at the level of significance (0.01) between the total degree of attachment patterns and the degree of self-assertion among secondary school students. b) the is a correlative relationship of positive statistical significance at the level of significance (0.01) between the pattern of secure attachment and the degree of self-assertion among secondary school students. c) there is a correlation of negative statistical significance at the level of significance $(0.01)$ between the pattern of fearful avoidance attachment and the degree of self-assertion among secondary school students. d) there is a correlation of negative statistical significance at the level of significance (0.01) between the preoccupied attachment pattern and the degree of self-assertion among secondary school students. e) There is a correlation relationship with a negative statistical significance at the level of significance $(0.01)$ between the dismissive-avoidant attachment pattern and the degree of self-assertion among secondary school students. Some attachment patterns, and not others, indicate self-assertion among secondary school students.
\end{abstract}

Keywords: attachment patterns - self-assertion- secondary school students.

DOI: $10.7176 /$ RHSS/10-12-03

Publication date:June 30th 2020

\section{Introduction}

Humans have an innate need for engaging in constant social interaction and establishing relationships with others, and the nature of attachment relationships depends on the quality of care and attention that a person has received in his childhood. Children instinctively build up initial perceptions for themselves and others specifically in terms of the worthiness of the self and expectations of others' reactions to the self which is known as internal working models of attachment, and that relies on the emotion of the caregiver towards the child and his response to the child needs. During the early childhood age, children develop significant connections with their caregivers, family members, and later with their peers. Over the years, several researchers have studied the effect of children's' attachment relationships on their performance, they found significant associations between the level of child-parent relationship consistency and stability during pre-school, elementary and middle school, and late adolescence (Ainsworth, 1985; Kobak \& Scerey, 2001; Hazan \& Shaver, 1987).

Bartholomew (1990) pointed out that young children may confound their perception of the attachment figure's availability and their love-worthiness, and that the Models of the self can be dichotomized as either positive (positive self-concept, the self as worthy of love and attention) or negative (negative self-concept, the self as unworthy) or can be viewed as (trustworthy, caring, available) and (rejecting, uncaring, distant). Accordingly, attachment relationship can be categorized into four styles: 1) secure (positive self-positive), 2) preoccupied (negative self-positive), 3) dismissing (positive self-negative), 4) fearful (negative self-negative). Therefore, early child-parent interaction may serve as a Model for negative patterns between personality and expectations in later relationships. According to Bowlby's theory, attachment is responsible for the child's emotional and social compatibility and development. He viewed the concept of attachment as a product of evolutionary processes that includes all the life stages of the children who establish bonds from attachment to their parents from childhood to adulthood. The central theme of attachment theory is that the quality of attachment relationships is stemmed from the interactions between children and the caregivers and it reflects the degree to which children can depend on the caregivers to provide them with companionship and to develop a sense of security to face any anxiety or threat, as well as establishing a safe basis from which they can explore what is around them. It is also considered a unique model of caregivers' availability and responsivity to a child's needs that results in a certain bond to the child (Kobak \& Sceery, 2001).

The development of research in the phenomenon of attachment has taken two directions: The first: It focuses on three main models that appear in situations that pose a threat to the security of the child: (1) Safe attachment: The tendency to determine the appropriate response to security threats and to approach the caregivers to spread reassurance. (2) Anxiety-avoidance attachment: the tendency to prevent emotion and behavior associated with 
security threats, to avoid people with whom the child relates, and to reject emotions associated with caregivers. (3) Anxiety - paradoxical, emotional attachment: a tendency towards anxiety about what threatens security, the response of the caregiver, and its availability in front of the child when he needs him and strives to be close to him, but with the failure to obtain reassurance from him (Lyons 1996). Where the second stage of the research focuses on understanding the compatibility of attachment in children with high risk, it indicates the lack of a consistent model of attachment behaviors, which is embodied in children subject to abuse and other forms of abuse (Stein, et al., 1998). While researchers were progressing in explaining these models of attachment behavior among children, some were also developing methods to evaluate the forms and patterns of attachment among adolescent families in late adolescence and peer relationships. Two forms of avoidance attachment were identified: dismissive versus fearful. Where attachment is rejected; By the tendency to separate from the attachment figure and to underestimate the importance of attachment and the feelings accompanying it. The fearful attachment is characterized by a tendency to avoid images of people related to him because of the fear of being ostracized and because of the desire to continue relationships and express their attachment behavior (Bartholomew \& Horowitz, 1991).

Adolescents with a pattern of safe attachment are characterized by having a positive pattern of self-confidence, a positive attachment to others, having the ability to form intimate relationships with others, and are more socially open than the unsafe people, and they have a desire to explore the environment around them. While people with insecure attachment, they have a negative self-model, negative relation toward others, low confidence in themselves, lack of closeness to others, mistrust of them, hesitant and sensitive, possessing a few friends, unwillingness and fear of exploring the surrounding environment (Bartholomew \& Horowitz, 1991). Cinott (1965) concluded that the adolescent's greatest fear comes from his loss of love from parents as well as from his feeling of deficiency. A teenager who feels anxious and eager for love, he may be tempted to engage in unwanted behavior such as aggressive behavior, theft, feelings of guilt, and love of revenge.

Most theories in psychology tend to generally agree that the types of early experiences to which a person is subject that may lead either to self-assertion or to self-unassertion. Therefore, self-assertion is not seen as a trait that appears suddenly in adolescence or early adulthood. Rather, self-assertion and non-self-assertion must be considered as an educated behavioral pattern formed by the individual learning to respond to social situations. The character of self-assertion develops gradually with the individual with age, because of the interaction of the child with his parents, and with important people in his life. If he is punished, for example, every time he raises his voice, then this leads the child to become introverted or aggressive and to suffer from fear when in some situation, he needs to raise his voice or say "no" because others consider such behavior an inappropriate behavior, and this entrenches the belief in the child that for him to be good in the eyes of his parents and others important in his life, he should be calm (Kenny, 1994).

One of the advantages of self-assertion to a high school student is that it empowers him to bear selfresponsibility as he can take responsibility for his decisions, feelings and actions, which give him strength in his interaction with others since he is able to communicate what he specifically and clearly desires, is ready to compromise, listens to others, has self-confidence and self-awareness, feels relaxed as a result of expressing his feelings clearly, provides feedback and accepts it openly and effectively, and enhances others and also receives it effectively (Hartley, 2005). Self-assertion is perceived to be a central factor in the student's social and academic life within the school and shows his ability to self-organize by organizing his thoughts, feelings, impulsive behavior control, and behavioral follow-up during task interaction and success. The student at this stage identifies a set of goals and attempt to adjust his ideas, emotions, and expectations to achieve those goals in the context of the changing environment and the challenges he faces (Conway, 2009; Perry, 2001.)

Self-assertion consists of a set of skills that are developed and acquired through different social institutions, and the family is considered to be the first and most important social institution to equip its children with these skills through a variety of attachment patterns they exercise that promote and develop these skills and thus contribute to the building up of their personalities from an early age and later enable them to face different situations. Based on the foregoing, attachment is a psychological phenomenon that has effects that should not be overlooked if we want a person to have a proper life, as it became clear how influential these patterns are in the emergence of mental disorders in adolescents to the extent that reveals the level of their ability to psychological and social compatibility later, Therefore, the researcher in this study tended to examine this relationship because it has negative future effects. Therefore, we had to recognize the relationship between attachment patterns (safe pattern - fearful pattern - busy mind style - and repulsive avoidant pattern) and the level of self-affirmation among secondary school students at Tla al-Ali Secondary School for Girls.

\subsection{The study problem}

Adolescent attachment patterns have received a lot of attention from specialists in the fields of psychology. (Markiewicz, Lawford, Doyle and Haggart, 2006) finds that the issue of attachment appears to be of critical importance in a teenager's life. Adolescence is the special period in which biological, mental, and social change takes priority. In human evolution, this is the last period in which neurological changes will be rapid. Furthermore, 
the relationship outside the family becomes intense, proceed towards independence from the parents, and the relationship with the peers becomes a priority during this period. The bonding behavior that begins during childhood may continue to affect adolescent throughout his life as relationship between mother and child is the first basic relationship.

Galehouse (2003) stressed the need to pay more attention to coordinating research efforts and interventions to develop the best strategies that contribute to the development of adolescent states, developing their active participation in making their present and future, and the ability to control and assert themselves. Adolescence is considered by some to be a period of intense emotions, which is generally characterized by instability, as adolescents at this stage have less warmth and acceptance, which in turn affects their self-assertion. The problem of the current study lies in revealing the patterns of attachment and its relationship to self-assertion among adolescents in Tla al-Ali Secondary School for Girls, and where the correlation can be taken as a standard for predicting self-assertion experienced by adolescents, which has made the researcher seek to shed light on this topic. Several studies have addressed the topic of self-assertion such as Wenfeng, et al (2015) pointed out that the predominant attachment pattern among students is the Secure attachment pattern, followed by the anxiety attachment pattern and finally the avoidance attachment pattern. The results indicated a positive statistically significant correlation between the secure attachment pattern and the high level of self-esteem and quality of relationship with peers and parents.Goodall (2015) found that there are no statistically significant differences between male and female in managing emotions or patterns of attachment and that there was a statistically significant correlation between the managing emotions and the insecure attachment patterns (anxiety and avoidance), self-assertion, the ability to manage emotion through each From stress, anxiety, self-esteem, and selfesteem. Where the results of Zhao, Young, Breslow, Michel, Flett, and Goldberg (2015) indicated that the secure attachment pattern ranked first, followed by the anxiety and avoidance attachment patterns as the most common relationship patterns for secondary school students; The results showed a negative correlation statistically significant between the pattern of secure attachment and social interaction with peers, and that there was a negative correlation statistically significant between the pattern of anxiety and avoidance and social interaction with peers. The results of a study conducted in (2015) by Lacasa, Mitjavila, Ochoa, and Balluerka) showed that there was a positive correlation statistically significant between the two types of attachment ( anxiety and avoidance and behavioral and psychological problems), and the presence of a negative correlation statistically significant between the pattern of secure attachment and behavioral and psychological problems. The results also showed that there were no significant differences statistically, the attachment patterns between ordinary adolescents and adolescents with behavioral and psychological problems and that there were no statistically significant differences in the attachment patterns attributed to the adolescent gender. The results of Hafshejani, et al. (3013) showed a statistically significant correlation between anxiety attachment, personality traits (neurotic - diastolic - openness to experiences - and conscience) and self-assertion. And that the anxiety attachment pattern and neuroticism contributed significantly to predicting self-assertion; and that improving the characteristic of conscience and avoidance attachment pattern can contribute to improving self-assertion skills.

The researcher noted through her work that female students in adolescence are affected by other factors that have made them behave in a way that may not be consistent with their convictions either to keep up with their peers or under the pressure of their caregiver. The researcher observed through her direct contact with them their lack of social skills and their self-assertion. This study comes as a realization by the researcher of the importance of studying the self-assertion of female students and linking them to their pattern of attachment and predicting the relationship between them.

\subsection{Study Hypothesis}

1- There is a correlation statistically significant between the degree of both attachment patterns and its overall degree for and the degree of self-assertion and its overall degree among female students in the secondary stage.

2- There is a significant correlation between the pattern of secure attachment and the degree of self-assertion of the female students in the secondary stage.

3- There is a significant correlation between the pattern of fearful attachment and the degree of self-assertion among female students in the secondary stage.

4- There is a significant correlational between the preoccupation type of attachment and the degree of selfassertion of the female students in the secondary stage.

5- There is a significant correlational between dismissive-avoidant attachment and the degree of self-assertion among secondary school students.

6- Some attachment patterns can be predicted to identify the degree of self-assertion among female students at the secondary stage. 


\subsection{The importance of the study}

The importance of this study lies in:

- Detecting a relationship between adolescence and attachment patterns in adolescents resulted from the effects of childhood attachment experiences.

- Reviewing the results of the latest research, theoretical studies that were conducted in this field with consideration to the desired benefit from them, and extrapolating what benefits our Arab society in the areas of child development and the traits shaped the personality in adolescence, and its implications on aspects of his future life.

- It may be beneficial in developing appropriate counseling programs for parents in the area of increasing the efficiency of their relationship with their children as well as setting out counseling programs for teenagers to increase their social skills, self-assertion, and train them on how to face stresses in the adolescence stage.

\section{Methodology}

This study aims to reveal the relationship between attachment patterns and self-assertion among high school students, and about the relational structure that distinguishes the nature of the relationship between attachment patterns and self-assertion. Therefore, the current study will rely on descriptive and explanatory approaches to explain this relationship.

\subsection{Study sample}

The study population consists of all secondary school students in Tla al-Ali Secondary School for Girls in Amman during the second semester of the academic year (2018-2019) who are according to the last statistic (1000) students. Where the random cluster study sample consisted of (250) female secondary school students in Tla al-Ali Secondary School in Amman.

Table (1): The study sample according to age.

\begin{tabular}{|l|l|l|l|l|l|l|}
\hline Age & Less than 14. & 15 & 16 & 17 & 18 & Total \\
\hline Frequency & 18 & 41 & 85 & 57 & 49 & 250 \\
\hline Percentage & 7.2 & 16.4 & 34 & 22.8 & 19.6 & 100 \\
\hline Mean & & & 15.4 \\
\hline Standard deviation & 4.12 \\
\hline
\end{tabular}

Table (1) indicated that the ages of female students in the basic study sample ranged between 14 years and less to 18 years, with mean of (15.4) years, and a standard deviation of (4.12).

Table (2): The study sample according to the study levels

\begin{tabular}{|l|l|l|l|l|}
\hline Study level & 1st secondary & 2nd secondary & 3rd secondary & Total \\
\hline Frequency & 93 & 107 & 50 & 250 \\
\hline Percentage & 37.3 & 42.8 & 20.0 & 100 \\
\hline
\end{tabular}

Table (2) shows that (37.2\%) of the respondents are in the first secondary class, while (42.8\%) of them are in the second secondary class and $(20 \%)$ of the study respondents in the third secondary class.

\subsection{Study tool}

\subsubsection{Attachment Patterns Scale}

The researcher used the attachment patterns scale that was prepared by (Amira Fikry Aydi, 2008) to identify adolescent attachment patterns. The attachment pattern scale consisted of (111) items. The items and thee instructions were translated into simplified Arabic to enable the sample to understand them at this age. The responses scale designed to measure three graded levels for each response which is (rarely - sometimes always).The scale consists of the following main dimensions: (1) Secure attachment: The behavior of the individual in this type of attachment is characterized by the fact that their relationships are characterized by love and affection with others, which increases their self-confidence in being more able to make their relationships succeed with their parents, they use the principle of mutual dependence in promoting psychological affinity between them and their parents. (2) Avoidance attachment: In this type of attachment, the individual is characterized by the fear of rejection from others, as if the other party says I will reject you before you reject me, and this appears in the form of extreme anger and aggression, criticism of others, influencing blame and loss, and viewing others as being unreliable and view himself as unloving and prone to depression. (3) Preoccupied attachment: the behavior of the individual in this type of attachment is characterized by that he lacks the independence and initiative required by the situation, is very dependent on others, lacks confidence, self-esteem, finds it difficult to form relationships, feels frustrated when interacts with others and is influenced by rejection, and tend towards depressive dependence, (4) Avoidant attachment: the individual's behavior in this type of attachment is characterized by that it underestimates the importance of needing to others and tries to deny the importance of love despite he feels that he deserves a close relationship with others and yet avoids extreme 
closeness to them and avoids face-to-face interactions and prefer to contact with others through e-mail. To obtain the total degree of attachment patterns, the scores for each of the four dimensions of the attachment patterns are calculated. The list has three responses (always - sometimes - rarely) and corresponds to it (3-2-1). Students are assured that there are no correct answers or a wrong answer because it is not considered a test and that they should answer in line with what they do, and that they should read and respond to each item by ticking an (X) in front of the item find it appropriate. The high score on the list indicates the presence of attachment relationships and the low degree indicates that it does not exist.

\subsubsection{Validity}

The researcher checked the validity of the attachment patterns scale on a group of (30) secondary school students at Tla al-Ali Secondary School for Girls in Amman who were from different levels of education to obtain the psychometric properties of the attachment patterns scale. To check the validity of the scale, it was calculated in two ways:

- Face validity: the scale was presented in its first form to a group of specialized arbitrators to check the suitability of the items to the dimension they will measure, language, and add or delete any paragraph. All the measurement scale paragraphs were approved by the arbitrators as they were appropriate and showed clear content validity.

- Intrinsic Validity: It is measured by calculating the square root of the test validity coefficient, as follows:

Coefficient of Intrinsic Validity $=$ (coefficient of test reliability) $1 / 2$

Coefficient of reliability $=(0,77) 1 / 2=0,88$

This means that the scale is valid and reliable.

2.2.1.2 Reliability

The researcher used the following methods to calculate the reliability of the scale:

(1) The test-retest: The researcher re-applied the test to a (16) students with an interval of (12) days, and she used the Pearson correlation coefficient to calculate the reliability factor. The reliability value was $(0.77)$ which is considered appropriate for the scale reliability.

(2) The internal consistency: The tool was applied to a random sample of (32) students. The variance was calculated using the Alpha Cronbach equation. The Alpha Cronbach equation is based on the variations of the test questions, and it requires that the test items measure only one characteristic. Therefore, the researcher calculated the reliability coefficient for each dimension separately, and then calculated the reliability coefficient of the overall scale. Table (3) shows the values of the Alpha Cronbach coefficients for each dimension separately and for the overall scale.

(3) Spilt-half reliability: where the scale was divided into two sections: the first section includes odd paragraphs, the second section includes even paragraphs, then the degrees of the two sections were used in calculating the correlation coefficient between them, so the reliability coefficient equal $(\mathrm{t} 1 / 2)$, then Spearman Brown equation used to calculate the whole test reliability coefficient, and the reliability coefficient value $(0,84)$ was high, indicating that the scale had a high degree of reliability.

Table (3): The values of the Alpha Cronbach coefficients for each dimension separately and for the overall scale

\begin{tabular}{|l|l|l|l|}
\hline $\mathrm{t}$ & Dimensions & No. Items & Alpha value \\
\hline 1 & Secure attachment & 26 & 0.77 \\
\hline 2 & Fearful avoidant attachment & 23 & 0.69 \\
\hline 3 & Preoccupied attachment & 35 & 0.81 \\
\hline 4 & dismissive-avoidant attachment & 27 & 0.73 \\
\hline 5 & Overall degree & 111 & 0.89 \\
\hline
\end{tabular}

As indicated in Table (3) the alpha coefficient ranged between (0.69) and (0.89) which are acceptable reliability coefficient and statistically significant.

2.2.2 Self-assertion Scale

The scale was originally developed by Wolpe \& Lazarus (1966); and was translated into Arabic by (Gharib, 1995). The scale consists in its original form of (30) items where in the Arabic form it included (25) items expressing how people behave in different situations. The scale measures the individual's ability to express his personal rights and feelings with the least amount of possible anxiety and without violating the rights of others (Gharib Abdel Fattah 2005, p. 36). The examiner is asked to put a sign (*) under the word (yes) or (no) according to the way he usually behaves. The researcher in this study checked the efficiency of the self-assertion scale on a group of (30) secondary school students in Tla al-Ali from different levels of education to extract the psychometric properties of the self-assertion scale.

To check the validity of the scale, the validity was calculated in two ways, as follows:

(1) Face validity: The scale was presented to a group of specialized arbitrators to check the paragraphs' appropriateness and the arbitrators approvement ranged between $(86 \%-98 \%)$.

(2) Discriminative Validity: By calculating the value of " $\mathrm{T}$ " for the difference between $27 \%$ of the lowest of the median and $27 \%$ of the median in the scale and the overall score, all values were statistically significant at the 
significance level of 0.01 .

To check the reliability of the scale, it was calculated in the following way: the reliability of the internal consistency of the scale: The validity of the internal consistency of the scale was verified by applying the scale to the exploratory sample consisting of (30) female high school students in Tla al-Ali Secondary School for Girls, where the Pearson correlation coefficient was calculated between each paragraph of the scale and the total score of the scale to which it belongs to. Table (4) shows the coefficient correlation of each item of the scale with the scale overall degree of the scale.

Table) 4): The correlation coefficient for each scale item with the scale overall score

\begin{tabular}{|c|c|c|c|}
\hline No. & Items & coefficient & Sig \\
\hline 1 & Would you express your position if someone in the queue crossed you? & 0.74 & 0.01 \\
\hline 2 & Is it hard for you to complain against a teacher for you? & 0.65 & 0.01 \\
\hline 3 & $\begin{array}{l}\text { Do you avoid complaining about bad service for example in a restaurant or } \\
\text { anywhere? }\end{array}$ & 0.71 & 0.01 \\
\hline 4 & Do you apologize too much? & 0.54 & 0.01 \\
\hline 5 & $\begin{array}{l}\text { If a friend criticizes you without justification, would you express your distress } \\
\text { immediately? }\end{array}$ & 0.68 & 0.01 \\
\hline 6 & Do you usually avoid people prone to control? & 0.74 & 0.01 \\
\hline 7 & $\begin{array}{l}\text { If you arrive later than a student's school activity, would you prefer to stand up rather } \\
\text { than go to a front seat where all attendance may see you? }\end{array}$ & 0.34 & 0.01 \\
\hline 7 & Can you disagree with someone who always sees himself as right? & 0.51 & 0.01 \\
\hline 8 & $\begin{array}{l}\text { If a colleague uses your special items without your permission do you discuss this } \\
\text { behavior with her? }\end{array}$ & 0.64 & 0.01 \\
\hline 9 & $\begin{array}{l}\text { If an adult sellers offer his item to you, you think that you do not need it, do you find } \\
\text { it difficult to say no? }\end{array}$ & 0.23 & 0.01 \\
\hline 10 & Do you generally express how you feel? & 0.63 & 0.01 \\
\hline 11 & $\begin{array}{l}\text { If you heard that one of your friends is spreading false rumors about you, would you } \\
\text { hesitate to confront her? }\end{array}$ & 0.75 & 0.01 \\
\hline 12 & Do you find it difficult to raise money for others, like donations? & 0.46 & 0.01 \\
\hline 13 & Do you usually keep your opinions to yourself? & 0.74 & 0.01 \\
\hline 14 & Do you find it difficult to start a conversation with a stranger? & 0.63 & 0.01 \\
\hline 15 & Can you express your love and passion of the people around you easily? & 0.85 & 0.01 \\
\hline 16 & $\begin{array}{l}\text { If the teacher misrepresents a piece of information or phrase that you think is wrong, } \\
\text { can you tell her? }\end{array}$ & 0.68 & 0.01 \\
\hline 17 & $\begin{array}{l}\text { If an older and respected person comes up with a phrase or information that you } \\
\text { strongly object to, do you express to him your point of view? }\end{array}$ & 0.46 & 0.01 \\
\hline 18 & $\begin{array}{l}\text { If a friend asked you for a request that you considered unreasonable, would you be } \\
\text { refused? }\end{array}$ & 0.72 & 0.01 \\
\hline 19 & $\begin{array}{l}\text { If you notice after leaving the place that you have given the rest of your money } \\
\text { wrong, will you return and explain that? }\end{array}$ & 0.84 & 0.01 \\
\hline 20 & $\begin{array}{l}\text { If a respectable and close relative bothered you, would you prefer to hide your } \\
\text { feelings than express them? }\end{array}$ & 0.56 & 0.01 \\
\hline 21 & $\begin{array}{l}\text { Do you find it easy for you to express your anger towards your female partners, to } \\
\text { express these feelings to members of the opposite gender of the boys? }\end{array}$ & 0.75 & 0.01 \\
\hline 22 & Is it difficult for you to say good things to others? & 0.32 & 0.01 \\
\hline 23 & Do you have a close friend with whom you can discuss almost everything? & 0.74 & 0.01 \\
\hline 24 & Do you like the person who, when he fails, tries again with new means? & 0.68 & 0.01 \\
\hline
\end{tabular}

Table (4) indicates that all correlation coefficients between the scale items and its dimensions were statistically significant at the significance level (0.01). These results confirm the consistency between the items and the dimensions of the scale.

\section{Results}

3.1 Results of the study hypothesis

1. "There is a correlation statistically significant between the degree of both attachment patterns and its overall degree for and the degree of self-assertion and its overall degree among female students in the secondary stage." To validate this hypothesis, the researcher used the simple correlation coefficient of "Pearson " between the raw 
grades of the sample respondents, on the scale of attachment patterns, and their overall degrees on the self-assertion scale to show the extent of the change in the patterns of attachment to the change in self- assertion as shown in Table (5).

Table (5): Correlation between the overall degree of attachment patterns and self-assertion among secondary school students

\begin{tabular}{|l|l|l|}
\cline { 2 - 3 } \multicolumn{2}{c|}{} & Self-assertion \\
\hline \multirow{2}{*}{ The overall degree of attachment patterns } & Correlation value & Sig \\
\cline { 2 - 3 } & 0.734 & 0.01 \\
\hline
\end{tabular}

Table (5) shows that there is a correlation relationship with a negative statistical significance at the level of significance (0.01) between the total degree of attachment patterns and the degree of self-assertion among high school students, which confirms the validity of the first hypothesis of the study.

2. "There is a significant correlation between the pattern of secure attachment and the degree of self-assertion of the female students in the secondary stage." To verify this hypothesis, the researcher used the simple correlation coefficient of "Pearson" as shown in Table (6).

Table (6): The correlation between the pattern of secure attachment and self-assertion among secondary school students

\begin{tabular}{|l|l|l|}
\hline \multirow{2}{*}{ Attachment patterns } & Self-assertion \\
\cline { 2 - 3 } & Correlation value & Sig \\
\hline Secure attachment & 0.726 & 0.01 \\
\hline
\end{tabular}

The results showed that there is a positive correlational at the significance level (0.01) between the pattern of secure attachment and the degree of self-assertion among secondary school students, which confirms the validity of the hypothesis.

3. "There is a significant correlation between the pattern of fearful attachment and the degree of self-assertion among female students in the secondary stage."

To confirm this hypothesis, the researcher used the simple correlation coefficient "Pearson " as shown in Table (7).

Table (7): The correlation between the Fearful avoidant attachment and self-assertion among secondary school students

\begin{tabular}{|l|l|l|}
\hline \multirow{2}{*}{ Attachment patterns } & Self-assertion \\
\cline { 2 - 3 } & Correlation value & Sig \\
\hline the Fearful avoidant attachment & 0.960 & 0.0 .1 \\
\hline
\end{tabular}

The results indicated that there is a correlative relationship with a negative statistical significance at the level of significance (0.01) between the pattern of fearful avoidant attachment and the degree of self-assertion among secondary school students, which confirms the validity of the hypothesis.

4. "There is a significant correlational between the preoccupation type of attachment and the degree of selfassertion of the female students in the secondary stage." To prove this hypothesis, the researcher used the simple correlation coefficient " Pearson" as shown in Table (8).

Table (8): The correlation between preoccupied attachment and self-assertion

\begin{tabular}{|l|l|l|}
\hline \multirow{2}{*}{ Attachment patterns } & Self-assertion \\
\cline { 2 - 3 } & Correlation value & Sig \\
\hline preoccupied & 0.930 & 0.01 \\
\hline
\end{tabular}

The results showed that there is a significant correlation with a negative statistical significance at the significance level $(0.01)$ between the preoccupied attachment pattern and the degree of self-assertion among secondary school students, which confirms the validity of the hypothesis.

5. "There is a significant correlational between dismissive-avoidant attachment and the degree of self-assertion among secondary school students." To verify this hypothesis, the researcher used the simple correlation coefficient "Pearson" as indicated in Table (9).

Table (9): The correlation between the pattern of dismissive-avoidant attachment and self-assertion among secondary school students

\begin{tabular}{|l|l|l|}
\hline \multirow{2}{*}{ Attachment patterns } & Self-assertion \\
\cline { 2 - 3 } & Correlation value & Sig \\
\hline dismissive-avoidant attachment & 0.116 & Nonsignificant \\
\hline
\end{tabular}

Table (9) shows that there is no statistically significant correlation between the pattern of dismissive-avoidant attachment and the degree of self-affirmation, which confirms the validity of the hypothesis.

Some attachment patterns can be predicted " not all) to identify the degree of self-assertion among female students at the secondary stage. 
To test the validity of this hypothesis, the researcher computed the simple linear regression equation to determine the extent of prediction of attachment patterns and their overall degree of self-assertion. Table (10) and Table (11) illustrate the results of this hypothesis.

Table (10) The extent of attachment patterns and their overall degree of self-assertion

\begin{tabular}{|l|l|l|l|}
\hline Dependent variable & \multicolumn{3}{|l|}{ Independent variables } \\
\hline \multirow{2}{*}{ Self-assertion } & $(\mathrm{R})$ & R squared (R2) & $(\mathrm{R} 2-)$ \\
\cline { 2 - 4 } & 0.979 & 0.959 & 0.959 \\
\hline
\end{tabular}

As indicated in Table (10) the explanatory independent variables (secure attachment pattern, preoccupied attachment pattern, fearful attachment pattern) were able to explain (0.96) of the variables that occur in selfassertion and the rest $(0.04)$ is attributed to other factors.

Table (11): T value to determine attachment patterns that predict self-assertion

\begin{tabular}{|l|l|l|l|l|}
\hline Dependent variable & Attachment pattern & Secure & Preoccupied & Fearful \\
\hline Self-assertion & B & 0.200 & $0.087-$ & $0.588-$ \\
\hline Coefficient value & 46.63 & 12.719 & 1.362 & $10.310-$ \\
\hline T value & 24.427 & 0.000 & 0.175 & 0.000 \\
\hline$\alpha$ & 0.000 & (1) &
\end{tabular}

Table (11) illustrates that the independent variables (secure and fearful attachment) were statistically significant and according to the t-test (at the level of significance $\mathrm{P} \leq 0.05$ ) whereas the independent variable ( preoccupied attachment) was not significant. Significantly in the multiple regression model according to the $\mathrm{T}$ test. It is clear from the previous that the predictive attachment patterns for self-assertion are: feared attachment predicted by $(58.8 \%)$, secure attachment predicted by $(20 \%)$, preoccupied attachment prediction with a rate of $(8.7 \%)$, which proves the validity of the sixth hypothesis : Some attachment patterns, not all, predicted the selfassertion of secondary school students.

\subsection{Discussion of results}

The results of the hypothesis were proven through statistical treatment as it indicated there is a correlation relationship with a negative statistical significance between the degree of both attachment patterns and its total degree, and the degree of self-assertion and its total degree of among female students in the secondary stage. The researcher interprets this result with that the negative relationship between the total degree of attachment patterns and the total degree of self-assertion results from the sum of two negative relationships of the insecure attachment pattern of self-assertion (fearful, preoccupied) versus one positive relationship of the secure style of self-assertion. This result is consistent with the results of (Deniz, et al., 2005), Huntsinger \& Luecken 2004 (Steven, 1998), Bifulcoet al. (2006) and Tamiki \& Takahashi (2013) which pointed out that the social skills of the persons with secure attachment are higher than the insecure and anxious people, hence they have satisfaction with their relationships and life. While persons with an insecure attachment have weak social skills and self-confidence. Individuals who are securely attached generally, have a positive perception of themselves and others that enables them to easily establish and maintain relationships with others, and to feel comfortable when interacting with them. As for individuals who have a negative perception, either towards themselves or towards others, they lack the social skills necessary to establish relationships or to maintain them as the basis of these relationships is selfconfidence and trust in others. This means that a secure attachment pattern is a good predictor of social skills. Theoretically, the researcher explains that the higher the degree of insecure attachment patterns (fearful, preoccupied), the lower the social skills and the lower levels of dependence and confidence in their relationships with others, which leads to a feeling of dissatisfaction with these relationships and making it difficult for them to interact socially. Thus, it leaves a negative impression on others. There is no doubt that the perception that others create about the individual has the deepest impact on the development of his self-esteem. On the other hand, selfesteem is considered the most important requirement for learning the skill of self-assertion. The results also confirm through statistical treatment the second hypothesis as there is a positive correlation with a positive statistical significance between the pattern of secure attachment and the degree of self-assertion among secondary school students. The results of this study are consistent with the results of the studies of Hafshejani, et al.(2013), Takahashi(2013), Tamaki, Jennifer, et al.(2001), Muris, et al.(2001), Cuebec (2004), Huntsinger \& Luecken (2004), and Deniz, et al.(2005) which showed that individuals with a secure pattern in their relationship with friends, compared to those with both anxious and avoidant patterns, enjoy that they spend more time in social interaction, and exercise a better quality of interactions in terms of the personal value of these interactions (or what these interactions mean to them ) that resulting satisfaction and enjoyment with others. The researcher explains this relationship that people who have a secure attachment pattern can easily trust others, and they are surrounded by close long-term relationships. They also tend to take positive views of their relationships, as they often acknowledge their consent and great adaptation in their relationships with others compared to other attachment patterns. These relationships are established as a social bond that enhances self-confidence, which increases the 
individual's conversational fluency and his ability to social interaction and disclosure of his rights and personal feelings. The results of the third hypothesis indicated that there is a correlation with a negative statistical significance between the fearful attachment pattern and the degree of self-assertion among secondary school students. The results of the study agreed with a study (Griffin, et al., 2002) that a teenager with fearless, avoidant, and anxious attachment patterns shows avoidance, lacks contact with others and suffers from feelings of inadequacy and anxiety. It also agrees with what (Voss, 1999) pointed out that a person with fearful, avoidant attachment pattern is characterized by weak socializing, lacks appropriate affirmative skills, easy exploitation of others, and involvement in self-criticism in stressful situations, which hinders overcoming pressures, and he withdraws in response to stressful situations. It also agreed with (Goonsen et al., 1999) which indicated that individuals with avoidance attachment felt more positive than being alone. The result also agreed with the results of (\& Takahashi, 2013 (Tamaki), which showed that the (rejectionist - fearful) attachment patterns were related to the low outcomes of many social skills and that the negative representation of others influenced the outcomes of social skills. The researcher interprets this as people with a fearful pattern suffer from doubts about their social and personal abilities which increase their feelings of anxiety about being close to others. Also, these individuals feel that the self does not deserve support, while others do not accept support in general, which indicates that they are keen to abandon and refuse thus they avoid intimate relationships. People with a fearful attachment have less self-esteem compared to the secure and rejectionist pattern. On the other hand, self-assertion is mainly based on self-esteem and individual vision of their abilities. Consequently, those with fearful fear suffer from a defect in their self-esteem and thus a lack of acquiring the skill of self-assertion.

The results also showed that there is a correlative relationship with a negative statistical significance between the preoccupied attachment pattern and the degree of self-assertion among secondary school students. This finding is consistent with what (Bowlby, 1980, p 246-250) indicated in his book Attachment and Lost: Part Three on Sadness and Depression when he explains the relationship between attachment disorder in children and adolescents. Where he pointed out that "those who have lived painful experiences in childhood and were deprived of establishing stable and secure love relationships with parents, and did everything they could to satisfy parents, including achieving their unrealistic expectations, and those who experienced losing a person become vulnerable to depression and psychological disorder, where he becomes The conceptual model they have for parents is that they are (not physically present and unavailable in times of stress and crisis, and are dismissive and punished, and the conceptual model about itself is unloved and incompetent. Which leads to expecting failure in future tasks and leads to a feeling of inability to establish or maintain an emotional relationship, and this deficiency continues in the next stages of development which leads to a psychological disorder. The researcher explains the inverse relationship that binds preoccupied pattern of attachment with self-assertion that people who have a preoccupied attachment style are not sure of the feelings of others towards them, the support they provide, and they suffer from fear and uncertainty which leads to their feelings of suspicion and lack of reassurance towards the attitudes of those around them. Which is reflected on their ability to assert themselves? Students with preoccupied attachment have negative thoughts about themselves and others that reflected negatively on their relationships and selfconfidence. On the other hand, self-assertion is the skill that emerges in personal relationships, so the individual's inability to accompany others prevents the individual from learning this skill. The results of the statistical treatment for the fifth hypothesis showed that there was no statistically significant correlation between the pattern of dismissive-avoidant attachment and the degree of self-assertion among secondary school students. The results of this study agreed with what the result of (Voss, 1999) that adolescent-avoidant attachment is characterized by (weak communication, a feeling of alienation, lack of participation in attachment relationships, more feeling lonely, associated with dangerous behaviors such as (aggression and theft), and protects himself from Feeling ostracized by taking a defensive stance and only recognizing positive self-characteristics, as he shows an emotional avoidance as a response to pressure. Likewise, it agreed with (Goonsen, et al., 1999) that indicated individuals with an avoidant attachment felt more positive than being alone. Huntsinger \& Luecken (2004) found that students with dismissive-avoidant attachment had a higher estimate than those with a fearful and anxious attachment. The results of the statistical treatment of the sixth hypothesis confirm that some types of attachment and not others predicted self-assertion among secondary school students. The results of this study are consistent with the results of (Deniz, et al., 2005), which concluded that self-expression could explain Attachment patterns. And that attachment patterns can explain (5.7\%) of the variance in self-expression. The researcher explains that the self-assertion is related to the pattern of secure attachment and preoccupied and fear according to the aforementioned relationships, where the aforementioned regression equation indicated that the higher the grades of secondary school students in the pattern of secure attachment and the lower the pattern of fearful attachment and preoccupied the higher their degrees in self-assertion. It must be pointed out that the dismissive-avoidant attachment pattern variable was not included in the multiple regression equation because its effect on self-assertion is very weak, and it interpret a small percent of variance in self-assertion. This result reflects the importance of the phenomenon of attachment and increases its significance as an important aspect of social growth in the process of developing individual's personality. The researcher believes that the beginning of the attachment bonds forms a central basis for the 
subsequent growth, and that the secure attachment is a protective factor against the negative impact of various problems and risk factors. Additionally, more efforts must be made to enhance this secure attachment, through which we may prevent the types of long-term problems associated with attachments patterns.

\section{Conclusion}

The study concluded several results that can be summarized as follows:

- There is a correlation with a negative statistical significance at the level of significance (0.01) between the total degree of attachment patterns and the degree of self-assertion among secondary school students.

- There is a positive correlation at the significance level $(0.01)$ between the pattern of secure attachment and the degree of self-assertion among secondary school students.

- There is a correlation with a negative statistical significance at the level of significance (0.01) between the fearful-avoidant attachment pattern and the degree of self-assertion among secondary school students.

- There is a correlation of negative statistical significance at the level of significance $(0.01)$ between the preoccupied attachment pattern and the degree of self-assertion among secondary school students.

- There is no correlation relationship with a negative statistical significance at the level of significance $(0.01)$ between the dismissive-avoidant attachment pattern and the degree of self-assertion among secondary school students.

- Some types of attachment and not others, predict self-assertion for secondary school students.

\section{Recommendations}

Considering the results of the current study, the researcher recommends the following:

1. Modify insecure student attachment patterns and work to support secure attachment patterns among secondary school students to achieve psychological and social compatibility.

2. Giving more attention to studying the factors affecting the relationship between attachment patterns and the skill of self-assertion to work to avoid the causes that lead to a weak positive relationship between them.

3. Holding courses and seminars by specialists in this field to learn how to use the pattern of safe attachment to develop and develop the skill of self-affirmation.

4. Enrich Arab Library with more research and studies related to attachment patterns and self-assertion.

\section{Suggested research and studies}

The researcher suggests referring to these researches that are related to the subject of the current study, but was not included in this study:

1. Preparing counseling programs that contribute to modifying unsafe attachment patterns among students.

2. Study attachment patterns and their relationship to the skill of self-affirmation in societies other than the student community, such as divorcees, prisoners, and residents in social care homes.

3. Study the relationship between attachment patterns and some other personal variables, such as psychological unity, psychological combustion, and emotional intelligence.

4. Study the relationship between attachment patterns and some other cognitive variables, such as creative thinking and social skills.

\section{References}

Ainsworth, M. (1985). Attachment across the Life Span. Bulletin of The New York Academy of Medicine.Vol.61, PP.792-812.

Aydi, Amira Fikry Mohamed. (2008). Attachment patterns and their relationship to psychological depression in adolescents (psychometric-clinical study). Master Thesis, Zagazig University.

Bartholomew, K. (1990). Avoidance of Intimacy: An Attachment Perspective. Journal of Social and Personal Relationships , Vol.7, PP.147-178.

Bartholomew. K.; \& Horowitz, L.M. (1991) . Attachment Styles Among Young Adults: A Test of four - category Model. Journal of Personality and Social Psychology, 61. 226-244.

Bowlby, J. (1980). Attachment and Loss, Volume 3, Loss, Sadness and Depression, Penguin Book .

Cinott, D.G. (1965). Between Parent \& Child, New York, Scribner Publisher .

Conway, A. (2009). Neurophysiological basis of Self-Regulation Children and Youth. Brain and Behavior.17. (4), pp.16-22.

Conway, A. (2009). Neurophysiological basis of Self-Regulation Children and Youth. Brain and Behavior.17. (4), pp.16-22.

Cuebec. (2004).Attachment Implication for College. Journal of Adolescence. Vol.6.pp.806-886.

Deniz, Hamarta, Ari (2005): An investigation of social skills and loneliness levels of university students with respect to their attachment styles in a sample of Turkish students, Social Behavior and Personality, 2005. 33(1), 19-32. 
Galehouse, Pamela (2003). The Influence of Temperament and Self Concept on Children's Disruptive Behavior. Dissertation Abstracts International, New York University.

Goodall, K.(2015). Individual differences in the regulation of positive emotion: The role of attachment and self esteem, Personality, and Individual Differences, 74,PP.208-213.

Goosense, Luc; Macron, Alfonse; Van Hoes, Sofie; Van de Westerner \& Oldie. (1999). Attachment styles and Loneliness in adolescence European, Journal of Educational Psychology, Vol.13, N.4, pp.529-542.

Griffin, D.; Dartholomew, K. (2002). Models of the Self and Other: Fundamental dimensions Underlying measures of Adult Attachment. Journal of Personality and Social Psycholoy, Vol, 67, PP, 433- 445.

Hafshejani, Zohreh; Fatrhizade, Maryam \& Yousefi, Zahra,(2013). The Multiple Relations Between Attachment Styles and Five Personality Traits with an Assertiveness in A Sample of Iranian Girl, Journal of Education Research and Behavioral Sciences, Vol.2 (10), PP.161-166.

Hazan, C., \& Shaver, P.R.(1987). Romantic Love Conceptualized as an attachment Process. Journal of Personality and Social Psychology, 52, pp.511-524.

Huntsinger, E. and Luecken, L. (2004). Attachment relationships and health behavior: The mediation al role of self self-esteem. Psychology and Health, 19, pp 515-526.

Kenny,M.(1994). Quality and correlates of parental attachment among late adolescents. Journal of Counseling Development,72, PP.399-404.

Kobak, R.; \& Sceery, A. (2001). Attachment In late adolescence: Working Models, Affect Regulation and representations Of Self and Others. Child Development, Vol. 59, PP.135-146.

Lacasa,F.; Mitjavila,M.; Ochoa,S.; and Balluerka,N.(2015). The relationship between attachment styles and internalizing or externalizing symptoms in clinical and non-clinical adolescents. Andesde Psychologies,3(2),PP.422-432.

Lyons, Ruth, K. (1996). Attachment Relationships Among Children with Aggressive Behavior Problems: The Role of Disorganized Early attachment Patterns. Journal of Consulting and Clinical Psycholoy, Vol.64, PP.64-73.

Markiewicz, D., Lawford, H., Doyle, A., and Haggart, N.(2006). Developmental differences in adolescents and young adult are use of mothers, fathers, best friends, and romantic partners to fulfill attachment needs. Journal of Youth and Adolescence, 35 (1), PP. 121-134.

Muris, Peter; Musters, Core; Van Melick, Marion \& Zwambag, Linda.(2001). Self Reported Attachment Style, Attachment in Young Adolescents, Journal of Experiment psychology, Vol.30, N.5, PP.809-818.

Perry, D. (2001). Self-regulation: The Second Core Strength. Early Childhood Today, 16, (3), 31-40.

Stein, H., Jacobs, N.J., Fergusom, K.S., Allen, J.G., \&Fonagy, P. (1998). What Do Adult Attachment Scales Measure? Bulletin of Menninger Clinic, Vol. 62, PP.33-82.

Steven, A, M. (1998). Personality correlates of adult attachment styles, Journal of Social Psychology, Vol, 138(3), pp 407-409.

Tamki, Koju \& Takahashi, Junichi. ( 2013). The Relationship Between Adult Attachment Style and Social Skills in Terms of The Four -Catrgory Model of Attachment Style, International Journal of Humanities and Social Science, Vol.3, No.19, PP.84-90.

Voss, K. (1999). Understanding Adolescent Antisocial Behavioral from Attachment Theory and Coercion Theory Pespective. Unpublished Doctoral Dissertation, Concordia University.

Wenfeng,R; Young,L.; Michel,N.; Flett,G., and Goldberg, J.(2015). Attachment style, relationship factors, and mental health stigma among adolescent. Canadian Journal of Behaviral Science, 47(4),PP.263-271.

Zhao,W.; Young,R.; Brslow,L.; Michel,N.; Flett,G.; Goldberg,J.(2015). Attachment style, relationship factors, and mental health stigma among adolescents. Canadian Journal of Behavioral Science, 47(4),PP.263-271. 